\title{
Proposed amendment of the International Code of Zoological Nomenclature to expand and refine methods of publication
}

\author{
International Commission on Zoological Nomenclature \\ c/o Natural History Museum, Cromwell Road, London SW7 5BD, UK ${ }^{1}$
}

For 250 years, taxonomists have relied on having access to physical copies of published works in order to verify information about taxa. The difficulty of tracking down publications can be a substantial impediment to taxonomic work, which has led some researchers to advocate modifying the codes of nomenclature, for plants and bacteria as well as for animals, to allow electronic publication of scientific names (Knapp et al. 2007, Wheeler \& Krell 2007).

Electronic publishing and access to online information can clearly accelerate progress in taxonomy (Wheeler 2008). Even when the fourth edition of the International Code of Zoological Nomenclature (ICZN 1999) was published, it was clear that electronic publication could not be ignored (Ride 1999, 2003). In all fields of science, however, long-term access to digital information has been and remains a significant concern (Anonymous 2001, Howe et al. 2008, Szalay 2008). Botanists have rejected proposals for electronic publication because of concerns for archiving and security from tampering (Zander 2004, McNeill 2006). Although some works printed on paper are rare, the number of instances in which no copies are known to survive is vanishingly small, so it certainly has been possible to reliably archive paper copies. Will we be able to say the same for electronic works 100 years from now? Can we have both rapid and effectively permanent access to publications and the information they contain?

The International Commission on Zoological Nomenclature (ICZN) considered these issues at a special session in Paris, August 23-25, 2008, preceding the XXth International Congress of Zoology (ICZ). The Commissioners voted to start the process required to amend the International Code of Zoological Nomenclature to allow electronic publication of new scientific names and other nomenclatural acts. A summary of the draft amendment was presented at the ICZ on August 27, during the Systema Naturae 250 symposium. The draft amendment was then refined via email discussion among Commissioners during the following month.

In Paris, Commissioners voted separately in favour of three principles relating to publication. None of these passed unanimously, but all had at least a two-thirds majority among the twelve voting.

- Electronic-only publications should be allowed, if mechanisms can be found that give reasonable assurance of the long-term accessibility of the information they contain.

- Some method of registration should be part of the mechanism of allowing electronic publication of names and nomenclatural acts.

- Physical works that are not paper-based (e.g. CD-ROMs, DVDs) should be disallowed.

One development favourable to the acceptance of electronic publication is the emergence of mature platforms for archiving electronic documents, such as Portico, which offers a permanent archive for electronic journals,

1. Correspondence should be addressed to the Executive Secretary, ICZN, iczn@nhm.ac.uk. See Appendix 1 for a list of Commissioners. 
and LOCKSS (Lots of Copies Keep Stuff Safe), an international, communal initiative based at Stanford University Libraries (Maniatis et al. 2005, Fenton 2006). These systems comply with the ISO standard for an Open Archive Information System (OAIS) and seek to assure the long-term retrievability of archived electronic publications, even when the publisher no longer supports distribution. The ICZN does not advocate these over other such archives, but sees them as examples of archiving technology that may prove acceptable to the zoological community.

The International Commission on Zoological Nomenclature therefore proposes the following amendment of the fourth edition of the International Code of Zoological Nomenclature (hereafter "the Code"), to allow electronic publishing coupled with archiving of works and registration of new scientific names. In addition to electronic publication, the proposal perforce addresses methods of publication in general. It is followed by an explanation of the procedure for amendment and adoption, and discussion of the reasoning behind the proposal. Comments from the community of zoologists are sought, whether to oppose, support, or suggest improvements and alternatives for the various parts of this proposal.

\section{PROPOSED AMENDMENT}

In the proposed amendment, normal font represents existing text of the Code. Text in italics is new text; titles that otherwise would be in italics are shown in small uppercase letters. Text in square brackets [ ] describes the changes proposed in a given section. The amendment affects Articles 8, 9, 10, 21, and 78, and the Glossary.

Article 8. What constitutes published work. A work is to be regarded as published for the purposes of zoological nomenclature if it complies with the requirements of this Article and is not excluded by the provisions of Article 9.

[Article 8.1 is revised to add electronic publication separately from methods that produce physical copies.]

8.1. Criteria to be met. A work must satisfy the following criteria:

8.1.1. it must be issued for the purpose of providing a public and permanent scientific record,

8.1.2. it must be obtainable, when first issued, free of charge or by purchase, and

8.1.3. it must have been produced in an edition containing simultaneously obtainable copies by a method that assures

8.1.3.1. numerous identical and durable copies (see Article 8.4), or

8.1.3.2. widely accessible electronic copies with fixed content and format (e.g. PDF/A, ISO Standard 19005-1:2005) (see Article 8.5).

[Articles 8.2 and 8.3 are unchanged. Article 8.4 is reformulated as the proposed 9.2, Article 8.5 is deleted, and Article 8.6 is simplified and merged under the proposed Article 8.4.]

8.4. Works issued as physical copies. Works issued as physical copies are subject to the following criteria:

8.4.1. Works printed on paper. After 2009, the only acceptable means of producing physical copies is by printing on paper using ink or toner. 
8.4.2. Works on CD-ROM or DVD. To be considered published, a work on CD-ROM or DVD

8.4.2.1. must have been issued after 1999 and before 2010, and

8.4.2.2. must contain a statement naming at least 5 major publicly accessible libraries in which copies of the CD-ROM or DVD were to have been deposited.

[A new Article 8.5 is added to address electronic works and add a requirement that they be archived.]

8.5. Works issued and distributed electronically. To be considered published, a work issued and distributed electronically must

8.5.1. have been issued after 2009,

8.5.2. state the date of publication in the work itself, and

8.5.3. be archived with an organization other than the publisher in a manner compliant with ISO standard 14721:2003 for an Open Archive Information System (OAIS), or the successors to that standard. (For documentation of the location of the archive, see Article 10.9.2.1.)

8.5.3.1. The archiving organization's website must provide a means to determine which works are contained in the archive.

8.5.3.2. The archiving organization must have permanent or irrevocable license to make the work accessible should the publisher no longer do so.

8.5.3.3. If it is found that the work was not deposited in an archive within one year after the work's stated date of publication, or that after the publisher or its successor no longer supports distribution of a work it cannot be recovered from an archive, the case must be referred to the Commission for a ruling on the availability of any names and nomenclatural acts contained in the work.

[A new Article 8.6 is added to allow the Commission to respond to changes in technology without need for amending the Code.]

8.6. New methods of publication and archiving. The Commission may issue Declarations to clarify whether new or unconventional methods of production, distribution, formatting, or archiving can produce works that are published in the meaning of the Code.

[Article 8.7 is unchanged. Recommendation $8 \mathrm{~A}$ is changed to accommodate electronic publishing; 8B, 8C, and $8 \mathrm{D}$ are added; and the current $8 \mathrm{C}$ through $8 \mathrm{E}$ are changed to $8 \mathrm{E}$ to $8 \mathrm{G}$, with the latter two otherwise unchanged and so not shown here.]

Recommendation 8A. Wide dissemination. Authors have a responsibility to ensure that new scientific names, nomenclatural acts, and information likely to affect nomenclature are made widely known. Authors can accomplish this by publishing in appropriate scientific journals or well-known monographic series, by entering new names and nomenclatural acts into the OFFICIAL REGISTER OF ZOOLOGICAL NOMENCLATURE (ZOOBANK), and by sending copies of their works to the ZOOLOGICAL RECORD. 
Recommendation 8 B. Minimum edition of printed works. A work on paper should be issued in a minimum edition of 25 copies, printed before any are distributed.

Recommendation 8 C. Electronic works. Ideally names and nomenclatural acts published in electronic works should also be published simultaneously on paper. Electronic works should be structured to allow automated indexing and data extraction.

Recommendation 8D. Content immutable. The content of a work is immutable once it is published. Publishers should not allow any changes to a work after its publication, even to correct typographical errors. Such changes automatically create a new work in the sense of the Code. Corrections should instead be made through notices of errata or other separate publications. This is particularly true for electronic works and works produced by print-on-demand. Second or other additional printings of a work should be clearly labeled as such, with date of publication stated in the work, whether or not any changes have been introduced.

Recommendation 8E. Public accessibility of published works. Copies of published works that contain new scientific names or nomenclatural acts, or information likely to affect nomenclature, should be permanently conserved in or by libraries that make their holdings publicly accessible.

[Article 9 is revised to add more details about what does not constitute published work.]

Article 9. What does not constitute published work. Notwithstanding the provisions of Article 8, none of the following constitutes published work within the meaning of the Code:

9.1. after 1930, handwriting reproduced in facsimile by any process;

9.2. after 1985, works produced by hectographing or mimeographing;

9.3. before 2000 and after 2009, works issued on laser disks such as CD-ROM and DVD;

9.4. photographs as such;

9.5. proof sheets;

9.6. microfilms;

9.7. acoustic records made by any method;

9.8. labels of specimens;

9.9. copies obtained on demand of an unpublished work [Art. 8], even if previously deposited in a library or other archive;

9.10. materials issued primarily to participants at meetings (e.g. symposia, colloquia, congresses, or workshops), including abstracts and texts of presentations or posters;

9.11. text or illustrations distributed by means of electronic signals (e.g. via the Internet), except those fulfilling the requirements of Articles 8.1 and 8.5.

Recommendation 9A. Authors to avoid unintentional publication in abstracts. Authors should not include names and acts affecting zoological nomenclature in abstracts of papers or posters to be presented at meetings. (For disclaimer of abstracts volumes, see Recommendation 8G.) 
[Under Article 10 (provisions conferring availability), proposed Articles 10.8 and 10.9 are added for names and nomenclatural acts published before and after 2009, with requirement of registration for the latter if published electronically.]

10.8. Availability of names and nomenclatural acts in electronic works. New names and nomenclatural acts cannot be made available in electronic works issued before 2010 (Article 8.5.1; see Article 10.9 for other requirements).

10.8.1. Where stability of nomenclature would be promoted thereby, a name or nomenclatural act appearing in such a work may be referred to the Commission for a ruling under the plenary power on its availability, if the work otherwise fulfils the requirements of Article 8.5.

10.9. Registration of names and nomenclatural acts. Registration in the OFFICIAL REGISTER OF ZOOLOGICAL NOMENCLATURE (Article 78.2.4) is required for a new scientific name published in an electronic work (Article 8.5) to be available. Additional requirements for availability of such names are:

10.9.1. the registration number assigned in the OFFICIAL REGISTER must be cited in the work itself, and

10.9.2. at least the following information must be recorded in the OFFICIAL REGISTER:

10.9.2.1. for the name of a taxon at any rank, sufficient bibliographic information to identify the work in which the name is proposed, and the name and Internet address of the archiving organization, and

10.9.2.2. for a species-group name, the depository for the name-bearing type and the location of that depository;

10.9.2.3. for a genus-group name, the type species;

10.9.2.4. for a family-group name, the type genus.

10.9.3. Registration of nomenclatural acts other than the proposal of new names in an electronic work is voluntary.

10.9.4. Names and nomenclatural acts published on paper may be registered voluntarily and retrospectively; such registration does not affect their availability.

10.9.5. Registration without publication in conformity with Articles 8 and 9 does not confer availability.

Recommendation 10B. Registration encouraged. Authors are encouraged to include registration numbers from the OFFICIAL REGISTER OF ZOOLOGICAL NOMENCLATURE for new names and nomenclatural acts that they introduce in paper-based publications, particularly if there is also an electronic edition.

[Under Article 21 (determination of date), 21.8 is revised to address advance electronic access to publications, and proposed Article 21.9 is added for works issued both on paper and electronically.]

21.8. Advance distribution of separates and preprints. Advance distribution of separates or preprints affects date of publication as specified by the following criteria:

21.8.1. Before 2000, an author who distributed separates in advance of the specified date of publication of the work in which the material was published thereby advanced the date of publication. 
21.8.2. The advance issue of separates after 1999 does not advance the date of publication, whereas preprints on paper, unambiguously imprinted with their own date of publication, are published works from the date of their issue, if they fulfil the criteria for publication in Article 8 and are not excluded by Article 9 (see Glossary: "separate", "preprint").

21.8.3. Some works are accessible online in preliminary versions before their final publication date. Advance electronic access does not advance the date of publication of a work.

21.9. Works issued on paper and electronically. A name or nomenclatural act published in a work issued in both print and electronic editions is available from the one that first fulfils the relevant criteria of availability.

[Under Article 78 (powers and duties of the Commission), proposed Article 78.2.4 is added to allow establishment of the Official Register.]

78.2.4. The Commission may establish and maintain an OFFICIAL REGISTER OF ZOOLOGICAL NOMENCLATURE, to record essential information about names and nomenclatural acts. The OFFICIAL REGISTER may be maintained in electronic or paper form. The OFFICIAL LISTS and OFFICIAL INDEXES may be maintained in the OFFICIAL REGISTER

[The following terms are proposed for addition to the Glossary.]

archive, n. A depository for works (q.v.); v. to place a work in an archive with the intent that it be permanently preserved there.

OFFICIAL REGISTER, $n$. An abbreviated title for the OFFICIAL REGISTER OF ZOOLOGICAL NOMENCLATURE, maintained by the Commission to record information about names and nomenclatural acts (see Article 78.2.4).

publication, electronic, $n$. A publication issued and distributed by means of electronic signals.

register, v. To enter into the OFFICIAL REGISTER information about a name, author, nomenclatural act, work, or other item tracked for purposes of zoological nomenclature.

registration number, $n$. A unique identifying number or alpha-numeric code assigned in the OFFICIAL REGISTER to a particular item.

ZOOBANK, $n$. The online version of the OFFICIAL REGISTER OF ZOOLOGICAL NOMENCLATURE.

\section{PROCEDURE FOR AMENDMENT}

The Constitution of the ICZN (Article 12.2) requires publication of notice of a proposed amendment of the Code in the Bulletin of Zoological Nomenclature $(B Z N)$, and submission of notice to at least three other journals, at least twelve months prior to the Commissioners' voting on the proposed amendment. The Constitution (Article 16.1.2) also requires a one-year period of comment from the zoological community. The one-year period for comment will start as soon as the first of the journals has published the text. The one-year period prior to voting will begin with publication in the issue of $B Z N$ for December, 2008.

The Commission will revise the amendment in light of comments received from zoologists (Constitution Article 16.1.4). Particular areas for discussion are highlighted below, but the Commission seeks comments on 
all aspects of the proposed amendment. Some comments will be published in BZN or posted on the ICZN website (www.iczn.org). Revised text of the amendment will also be posted there, and in the ICZNwiki (iczn.ansp.org).

Formal comments should be sent to Dr Ellinor Michel, Executive Secretary of the ICZN (iczn@nhm.ac.uk) or to Dr Gary Rosenberg, chair of the ICZN Editorial Committee (rosenberg@ansp.org). Zoologists may also contact ICZN Commissioners directly for informal discussions (Appendix 1; http://www.iczn.org/Commissioners.htm).

Assuming that sufficient consensus is reached in the zoological community, the revised amendment will be presented at the International Union of Biological Sciences (IUBS) meeting in Cape Town, South Africa, in November, 2009 for provisional ratification under Constitution Article 16.1.5.1. Final adoption would then be by a vote of the Commissioners.

\section{DISCUSSION}

Although this proposal affects several Articles of the Code, it is presented as a single amendment. If presented as multiple amendments, each would be subject to separate vote, but the intention is to present an integrated package addressing issues of methods of publication.

In formulating the amendment, Commissioners have been concerned with issues of verifiability and encouragement of best practices. With printed publications it generally has been possible to verify from the work itself whether the names and nomenclatural acts it contains are available (leaving aside the problem of doctoral theses). With the advent of electronic publication, this distinction has been blurred. It is not unusual today to receive a PDF of an article without knowing if the journal in which it appeared was printed on paper or issued only electronically. This leaves the user unable to judge availability.

Registration of names is one means of addressing this issue, although it introduces dependency on an outside agency, as does the requirement for archiving of works. To obviate the need to check both the Official Register and an archive to determine whether a name is available, the proposed amendment requires that the location of the future archive for a work be stated when the name is registered, and that the registration number be given in the original publication. This should allow the user to determine from the work itself that a name fulfills these requirements. Further considerations on archiving, registration, and other aspects of the proposed amendment are presented below in order of the number of the proposed article.

\section{Formats for electronic publication (proposed 8.1.3.2)}

It is difficult to specify which formats can be accepted for electronic publication. E-journals that have a fixed and final published form clearly are appropriate outlets for publishing nomenclatural works, whereas continuously modifiable forms such as online databases and interactive keys are not. In specifying "fixed content and format", the intention is that the same text and illustrations should appear with the same pagination and proportions whenever a copy of the work is viewed, recognizing that different software will not render a page identically on different computers. Also, external links are excluded under "fixed content"; linked material such as 3-D tomographic images or videos of behaviour would not be considered part of a publication. Information necessary to confer availability must be in the work itself.

\section{Works printed on paper (proposed 8.4.1)}

The third edition of the Code excluded electrostatic and xerographic methods from conventional printing, in Article 9(3). The fourth edition does not mention these methods, and despite providing cut-off dates for the 
acceptability of methods other than conventional printing in Articles 8.4 and 8.5, does not define or restrict conventional printing. The effect is to make works produced by electrostatic and xerographic printing acceptable retroactively.

In practice, zoologists have accepted as published anything that looked like a journal article or monograph, whether produced by letterpress, inkjet printer, laser printer, or xerography. They have not accepted printing on thermal paper or output from dot-matrix printers, presumably because they could judge that they did not fulfil the requirements of Article 8.1.1.

With the proliferation of printing techniques, it is impractical to ask the user of a work to judge how it was produced. The proposed amendment therefore has a single, simplified article governing printing of works after 2009, accepting all forms of ink or toner on paper. The exceptions are hectographing and mimeographing, which it is clear the Code intended to exclude after 1985, and which are readily identified as reproductions of typewritten works. This exclusion is transferred to Article 9.2 in the proposed amendment, allowing the current Article 8.4 to be dropped.

The Commission is not aware of paper-based works that zoologists have judged not to be published because of electrostatic, xerographic, or other unconventional methods of production. Therefore, the proposed revision drops the current Article 8.5. If there are such examples, we would like to hear of them. This will help in assessing the advisability of this proposed simplification of the Code.

\section{CD-ROM and DVD (proposed 8.4.2)}

The fourth edition of the Code does not specifically refer to CD-ROM or DVD in its legislative text, but the Introduction (p. xxvii) refers to "read-only laser disks", so clearly the intent was to include them as methods of production that do not employ printing on paper (current Article 8.6). As relatively few works have been published on CD-ROM or DVD, and the long-term durability and readability of those media are controversial, the proposed amendment disallows them after 2009.

It was in principle possible for a work on CD-ROM to have been issued before 2000 under Article 8.5 (then Article 8d), as a method other than conventional printing. The Commission, however, is not aware of any that contain the statements required under Articles 8.5.2 and 8.5.3. If such exist, they should be brought to the attention of the Commission.

\section{Archiving (proposed 8.5)}

The library community shares with the taxonomic community concern for long-term accessibility of published works, and has played a leading role in the development of archives such as Portico and LOCKSS mentioned in the Introduction. Both of these are curated, dark archives; "dark" in that a work will be released by the archive only if the publisher no longer supports distribution; "curated" in that the archive takes responsibility for migrating the content to new formats as needed to address changes in technology. This means, however, that the original format (e.g. PDF) may not be preserved even though the content is preserved.

Zoologists may be surprised to know that a number of taxonomic journals are already in such archives, for example, The Auk, Copeia, Journal of Paleontology, Journal of Molluscan Studies, Zoologica Scripta, and Zoological Journal of the Linnean Society. For Portico and LOCKSS, the titles held can be determined from their websites ${ }^{2}$, but as yet, it is not possible to tell what range of years or specific issues are held unless one has audit-level access. The Commission intends to learn more about these and other archives to determine whether their mode of operation is, or can be modified to be, compatible with the needs of zoologists.

2. For titles committed to Portico and LOCKSS, see http://www.portico.org/about/committed_titles_alpha.html and http://www.lockss.org/lockss/Publishers_and_Titles_List. 
When it is found that the requirement for archiving was not fulfilled, the proposed amendment (8.5.3.3) requires that the case be referred to the Commission. While there is concern that this might lead to an increased number of cases, it seems necessary to formally decide whether a work was published. Otherwise, some names and acts might be rejected, while others in the same work might still be used by those unaware of the problem. Also, some names in a work might be better known than others, so it may be necessary to conserve some and reject others. Formal action by the Commission is the best way to achieve consistent results in such situations.

\section{Recommendations for Article 8}

A suggested minimum number of 25 copies in a printed edition is added in proposed Recommendation $8 \mathrm{~B}$ to address several concerns. One is that "numerous" in the current and previous editions of the Code is undefined. Article 8.6 of the current Code has been taken by some workers as establishing 5 copies as the minimum number, but that Article applies only to works not printed on paper. Some authors of electronic works currently use print publication of a small number of copies to satisfy requirements of availability, but it has been controversial whether such works should be considered "obtainable" (Article 8.1.2) if sent only to a few colleagues. A similar route might be taken by authors finding that their electronic publications failed to meet requirements for archiving or registration. Also, Article 21.8 allows date of publication to be advanced by distribution of preprints, so this recommendation provides guidance on a minimum number to distribute.

A related issue is print-on-demand. Print-on-demand in principle could be used to produce a traditional print-run. One could order "numerous" copies of a work (or 25 under the proposed revision), so the method fulfils the requirement of producing "simultaneously obtainable" copies (Article 8.1.3). Yet print-on-demand can also be used to produce a single unique copy of a work, which would not be published under the Code. Because there could be multiple versions of a work, as the author finds and corrects errors, print-on-demand does not "assure" identical copies. This is not a new problem: there are works known to have been produced in multiple silent editions, with changes between them that affect nomenclature-but each of those editions was in multiple copies. The ease and inexpensiveness of production without need for physical storage make such problems much more likely with print-on-demand. Furthermore, often the user of a work will not know that it was produced by print-on-demand and so subject to these concerns.

Concerns about the ease of modifying works produced by print-on-demand apply with even more force to works distributed electronically. If the text distributed by a publisher were to be silently modified in aspects that affect zoological nomenclature, it would be difficult establish what the original text was, and on what date the modifications occurred, especially since there likely would not be date-stamped copies in libraries. Proposed Recommendation 8D therefore urges publishers not to allow changes to works after publication, particularly for electronic and print-on-demand works, and to handle any needed corrections through errata notices or other separate publications. The requirement for archiving within one year also limits the time during which silent changes might be made to electronic publications.

\section{Registration of names (proposed 10.9)}

The Commission intends ZooBank (www.zoobank.org) to be the Official Register of Zoological Nomenclature. While ZooBank has the potential to benefit taxonomy by making nomenclatural information readily accessible (Polaszek et al. 2005), the proposed amendment focuses on registration as a mechanism to make it readily verifiable that some of the criteria of availability have been fulfilled.

In particular, the user of an electronic work can determine that the requirements for archiving and registration have been fulfilled when registration numbers are given in the work. This also avoids a "limbo" period during the one year allowed between publication and archiving (proposed article 8.5.3.3), when it would not 
be possible to tell if a work was published under the Code. The presence of the registration number allows the user to accept that the archiving requirement has been fulfilled, but the user can also directly examine the archive if desired. Should a work prove not to have been archived, a decision by the Commission would be needed, as explained above.

Although some authors have advocated that registration be mandatory for all names (Wheeler \& Krell 2007), the proposed amendment requires registration only for names published electronically. Those who wish to publish on paper may continue to do so, without the need for archiving or registration. The proposal does not require registration for other nomenclatural acts, such as lectotype and neotype designations and first revisers' choices, as it is likely that this could cause problems, with authors neglecting to register many such acts. We hope that registration of names and acts will become a community standard, enforced by reviewers and editors, as has submitting genetic sequences to GenBank and publication of GenBank numbers.

\section{Works issued on paper and electronically (proposed 21.9)}

For the purposes of the Code, "electronic publication" and "electronic-only" publication are effectively synonymous. An electronic publication is not the same work as the printed edition of that publication, and each edition has its own criteria of availability. This does not mean that names and other nomenclatural acts are at risk of being published twice. The same situation already exists with repaginated reprints, or second printings that still state "new species". In practice, when the relevant content is the same, most taxonomists deem that only one name was introduced or that only one nomenclatural act has occurred. This needs to be made explicit in the fifth edition of the Code, but as this is a broader concern than electronic publishing in itself, it is not treated here.

In cases where there are differences between versions (e.g., different spellings of a name, different specimens designated as the holotype), the versions are treated as different works. Divergence between electronic and online versions will surely be common (e.g., black-and-white images in print, colour online), but such differences will probably only rarely affect availability of names and nomenclatural acts.

\section{References}

Anonymous. (2001) The future of the electronic scientific literature. Nature, 413, 1, 3.

Fenton, E. (2006) Preserving electronic scholarly journals: Portico. Ariadne, 47. Available from http://www.ariadne.ac.uk/issue47/fenton/ (accessed 29 September 2008).

Howe, D., Costanzo, M., Fey, P., Gojobori, T., Hannick, L., Hide, W., Hill, D.P., Kania, R. Schaeffer, M., St Pierre, S., Twigger, S., White, O. \& Rhee, S.Y. (2008) The future of biocuration. Nature, 455, 47-50.

International Commission on Zoological Nomenclature (1999) International Code of Zoological Nomenclature. International Trust for Zoological Nomenclature, London, xxix $+306 \mathrm{pp}$.

Knapp, S., Polaszek, A. \& Watson, M. (2007) Spreading the word. Nature, 446, 261-262.

Maniatis, P., Roussopoulos, M., Giuli, T.J., Rosenthal, D.S.H. \& Baker, M. (2005) The LOCKSS Peer-to-Peer Digital Preservation System. ACM Transactions on Computer Systems, 23, 2-50.

Available from http://www.eecs.harvard.edu/ mema/publications/TOCS2005.pdf (accessed 29 September 2008).

McNeill, J. (2006) XVII International Botanical Congress: Summary report of the actions of the nomenclatural section of the Congress - Vienna, Austria 12-16 July, 2005. Botanical Electronic News, 356.

Available from http://www.ou.edu/cas/botany-micro/ben/ben356.html\#3 (accessed 29 September 2008).

Polaszek, A. et al. (2005) A universal register for animal names. Nature, 437, 477.

Ride, W.D.L. (1999) Introduction. In: International Commission on Zoological Nomenclature, International Code of Zoological Nomenclature. International Trust for Zoological Nomenclature, London, pp. xix-xxix.

Ride, W.D.L. (2003) The International Code of Zoological Nomenclature, 4th edition - what next? In: Legakis, A., Sfenthourakis, S., Polymeni, R. \& Thessalou-Legaki, M. (Eds.), The New Panorama of Animal Evolution: Proceedings XVIII International Congress of Zoology. Pensoft, Sofia and Moscow, pp. 673-682.

Szalay, A. (2008) Preserving digital data for the future of eScience. Science News, 174(5), 32. 
Wheeler, Q.D. (Ed.) (2008) The New Taxonomy. CRC Press, New York, xi + 237 pp.

Wheeler, Q.D. \& Krell, F.T. (2007) Codes must be updated so that names are known to all. Nature, 447, 142.

Zander, R.H. (2004) Report of the Special Committee on Electronic Publishing with two proposals to amend the Code. Taxon, 53, 592-594.

\section{APPENDIX 1: International Commission on Zoological Nomenclature}

President: Prof. Denis J. Brothers

Vice-President: vacant

Executive Secretary: Dr Ellinor Michel

Chair of Editorial Committee: Dr Gary Rosenberg

Chair of ZooBank Committee: Dr Frank Krell

Commissioners:

Dr Miguel Alonso-Zarazaga (Spain; Coleoptera)

Dr Nina G. Bogutskaya (Russia; Ichthyology)

Prof. Philippe Bouchet (France; Mollusca)

Prof. Denis J. Brothers (South Africa; Hymenoptera)

Prof. Daphne G. Fautin (U.S.A.; Coelenterata, Cnidaria)

Dr Mark J. Grygier (Japan; Crustacea, Myzostomida)

Dr Bruce Halliday (Australia; Acari)

Dr Maurice Kottelat (Switzerland; Ichthyology)

Dr Frank Krell (U.S.A.; Coleoptera)

Dr Sven O. Kullander (Sweden; Ichthyology)

Prof. Dr Gerardo Lamas (Peru; Lepidoptera)

Dr Susan Lim (Malaysia; Parasitology, Monogenea)

Prof. Alessandro Minelli (Italy; Myriapoda)

Dr Peter K. L. Ng (Singapore; Crustacea, Ichthyology)

Dr Thomas Pape (Denmark; Diptera)

Dr Laszlo Papp (Hungary; Diptera)

Prof. David J. Patterson (U.S.A.; Protista)

Dr Richard Pyle (U.S.A.; Ichthyology)

Dr Gary Rosenberg (U.S.A.; Mollusca)

Prof. Pavel Štys (Czech Republic; Heteroptera)

Mr Jan van Tol (The Netherlands; Odonata)

Dr Zhi-Qiang Zhang (New Zealand; Acari)

Contact information is available from http://www.iczn.org/Commissioners.htm. 